\title{
Comparative Study of Viability in Seeds of Six Genera of Family Fabaceae
}

\author{
${ }^{1}$ Dr. Geetika Singh*, ${ }^{2}$ Gundeep kaur, ${ }^{3}$ Komalpreet \\ ${ }^{1}$ Assistant professor in MCM DAV College \\ ${ }^{1,2,}$ Student MCM DAV college, Chandigarh, India
}

\begin{abstract}
The present study was undertaken with the aim to study the germination of seeds of family fabaceae. Plants of family Fabaceae also called as bean family are economically important family of flowering plants. The family is widely distributed, and is the third-largest land plant family in terms of number of species, behind only the Orchidaceae and Asteraceae. The influence of light, water, temperature and $\mathrm{pH}$ on germination were also analysed. The seeds of Glycine max, Vigna radiata, Vigna munga, Cicer arientum, Lens culinaris and Trigonella foenum-graecum were studied. This study of germination revealed that germination was essentially complete after 14 days. Germination percentage, vigour index were studied and comparatively analysed. TTC test were conducted in all the six species to study their level of cellular respiration. Out of all the genera Vigna radiata and Trigonella foenum-graecum showed the best viability.
\end{abstract}

Keywords: Germination, Fabaceae, TTC test, Vigour index

\section{INTRODUCTION}

Legumes are grown agriculturally, primarily for their grain seed called pulse, for livestock forage and silage, and as soil-enhancing green manure. Well-knownlegumes include alfalfa, clover, peas, beans, lentils, lupin bean, mesquite, carob, soybeans, peanuts and tamarind. Fabaceae is the most common family found in tropical rainforests and in dry forests in the Americas and Africa. In the chain of events that lead to seed germination is the imbibition of water. Many types of seeds will germinate as soon as they are provided with a favorable environment of moisture, air and warmth. Other sound seeds are prevented from doing so by various barriers such as the inability of water to penetrate seed coats, internal physiological conditions, or a combination of these factors. Germination of many seeds is retarded only by impermeable coats which hinder the admission of water. If these coats are not subjected to pretreatment, germination can be erratic and prolonged, sometimes extending over a period of many years. Deterioration is evident as a reduction in percentage germination, produce weak seedlings, loss of vigour, become less viable and ultimately seed death ${ }^{1}$. Seed quality is influenced by numerous factors that occur in the field before harvesting and during harvesting, drying, processing and storage. The losses are worsened if seeds are stored at high temperature and high relative humidity conditions ${ }^{2}$

Commonly, seed deterioration is reported to accompany changes in enzyme activity during ageing ${ }^{3}$. Although seed deterioration is generally accompanied by loss of enzyme activity ${ }^{4}$, a few hydrolytic enzymes like - amylases and proteases show an increase in their activity.In legumes, dormancy is mainly ensured by the hard and impermeable seed coat, a characteristic referred to as hardseededness. Mature seeds which do not germinate when placed in conditions, normally regarded as favourable to germination, are referred to have primary dormancy. On the other hand seeds which germinate and lose their readiness to germination are referred to have secondary dormancy. Secondary dormancy is often induced by extremely high or low temperatures. It is well known that seeds of annual plants have cycles of dormancy and non-dormancy depending on the weather conditions The present study was undertaken with aim to study the variation in germination of six genera of legumes and the effects of external factors on their germination ability.

\section{MATERIAl AND MethodS}

Seeds of all the genera i.e Glycine max, Vigna radiata, Vigna munga, Cicer arientum, Lens culinaris and Trigonella foenum-graecum were collected in February 2017 from Chandigarh. Germination test in petridish was done. Twenty randomly selected seeds were surface sterilized by soaking them in 


\section{Dr. Geetika Singh et al.}

$0.5 \% \mathrm{HgCl} 2$ for two minutes followed by thorough washing in running water and finally in distilled water. These surface sterilized seeds were placed equidistantly in pre sterilized petri dishes $(9.0 \mathrm{~cm})$ lined with filter paper. These petri dishes were maintained at $28+/-2$ in dark in BOD incubator. Germination percentage and emergence of radicle was considered as an indicator of germination. The observations for number of seeds germinated and their respective root and shoot length were recorded. The seed germination study of all the six genera were conducted in a completely randomized design with seven treatments replicated thrice on two varieties. For germination tests air-dried seeds were disinfected first in $0.04 \% \mathrm{HgCl}_{2}$ and washed thoroughly. Observations were made on number of days for germination required for the first count; radicle length, plumule length, germination initiation and percentage for the two varieties and data were analysed using ANOVA.

Germination percentage $=($ Total number of seeds germinated $\times 100)$

Total number of seeds in all replicates

Vigour Index $=$ Germination percentage $\times$ Root length in $\mathrm{cms}$.

Tetrazolium test $=$ The study was conducted in a completely Randomized Design replicated thrice. To ensure that seeds used for the experiment were viable, a seed viability test using the tetrazolium technique was conducted. Three replicates of 20 seeds each were tested using the procedure of Peter (2000). Seeds were imbibed for $24 \mathrm{~h}$ in water, cut along the margin without damaging the embryo and soaked in a $0.1 \%$ solution of 2,3,5-triphenyl tetrazolium chloride solution for $18 \mathrm{~h}$ at $25^{\circ} \mathrm{C}$ in the dark. The seeds were removed from the TTC solution and washed with distilled water. Seeds were then viewed under a light microscope to observe the stained embryos. Viable seeds appeared bright red in colour.

\section{RESUltS AND DiscuSSION}

In the present study twenty dried seeds of all the genera of legumes were used Screening of 100 seeds showed that $85 \%$ were healthy and $14 \%$ shrunk and $1 \%$ insect damaged. Prior to germination studies the seeds were surface sterilized by soaking them in $0.5 \%$ mercuric chloride $\left(\mathrm{HgCl}_{2}\right)$ for two minutes followed by thorough washing in running water. They were later rinsed with distilled water 2-3 times. Ten randomly selected surface sterilized seeds were placed equidistantly in pre-sterilized petridishes $(\varnothing 9.0 \mathrm{~cm})$ lined with filter paper. One set of seeds were placed in petridishes, on filter paper soaked in distilled water as control. The entire experiment was conducted in laboratory condition in seed germinator where temperature was maintained at $28^{\circ} \mathrm{C} \pm 2^{\circ} \mathrm{C}$.

Fig1. Germination percentage and vigour index in seeds of all genera of legumes.

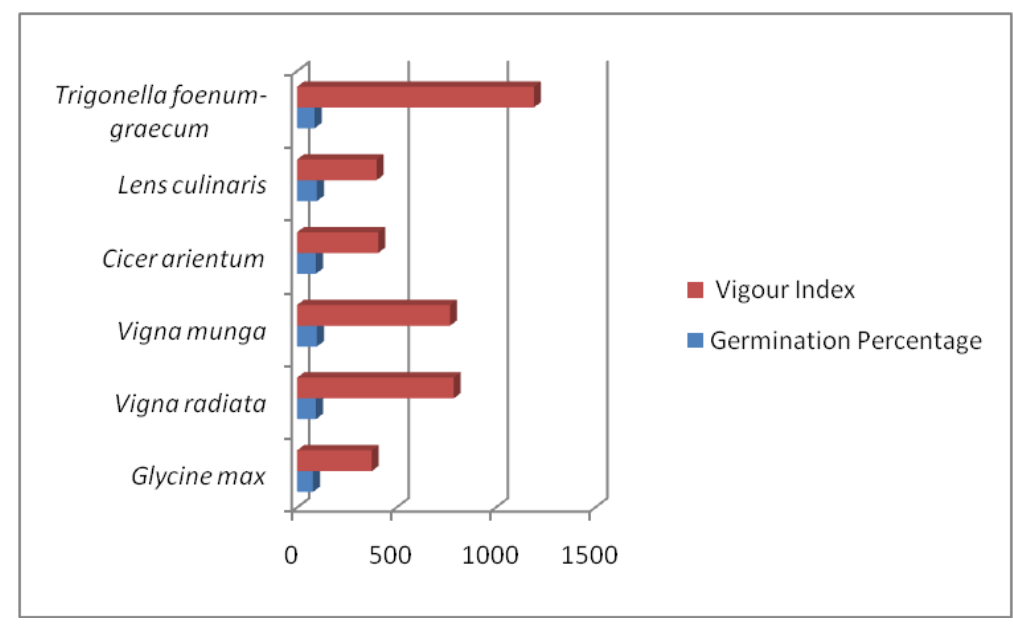

Table1. Germination percentage, root length and vigour index of six genera of legumes.

\begin{tabular}{|c|c|c|c|}
\hline Type of Seed & Root length(cm) & Germination Percentage(\%) & Vigour Index \\
\hline Glycine max & $4.7 \pm 1.2$ & 80 & 376 \\
\hline Vigna radiata & $8.3 \pm 0.8$ & 95 & 788.5 \\
\hline Vigna munga & $7.7 \pm 0.78$ & 100 & 770 \\
\hline Cicer arientum & $4.3 \pm 0.54$ & 95 & 408.5 \\
\hline Lens culinaris & $4 \pm 0.2$ & 100 & 1192.0 \\
\hline $\begin{array}{c}\text { Trigonella foenum- } \\
\text { graecum }\end{array}$ & $13.5 \pm 1.5$ & 88.3 & \\
\hline
\end{tabular}




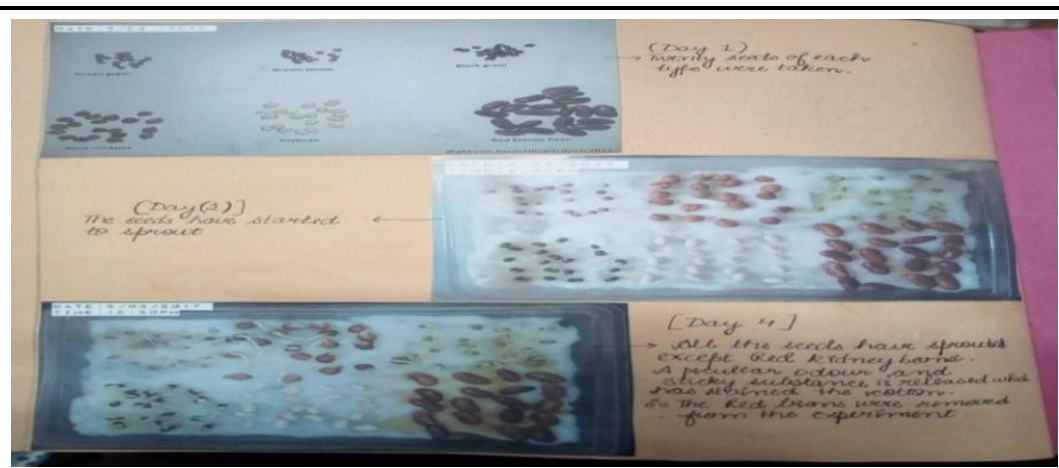

Figure2. Showing germination on $1^{\text {st }}, 2^{\text {nd }}$ and $3^{\text {rd }}$ day of all the six genera of legumes

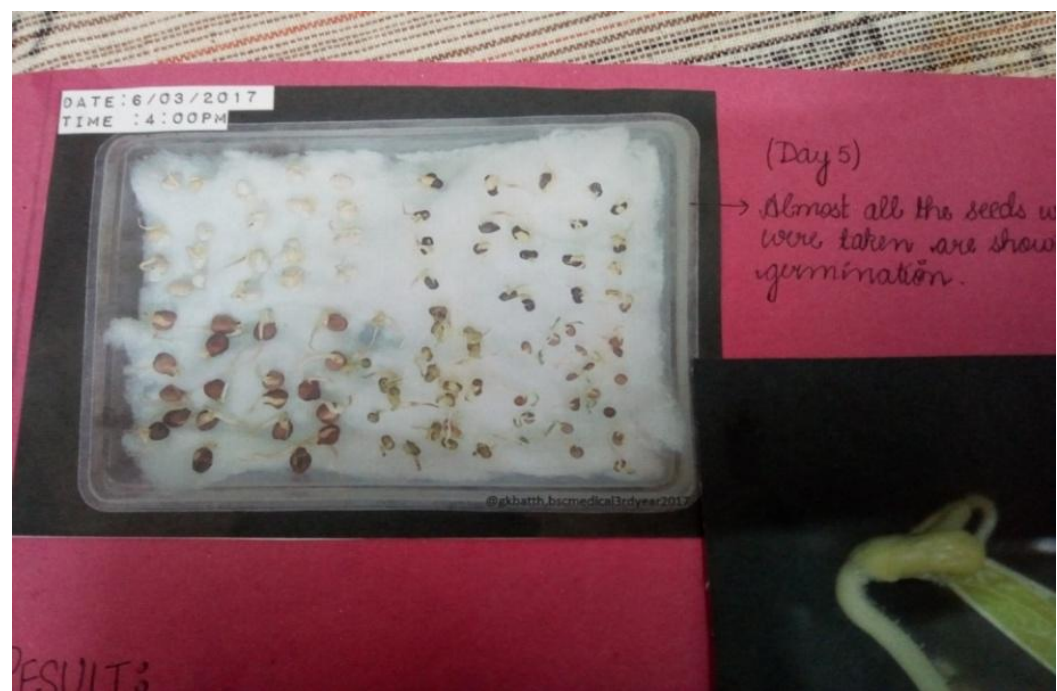

Figure3. Showing germination on $5^{\text {th }}$ day of all the genera of legumes

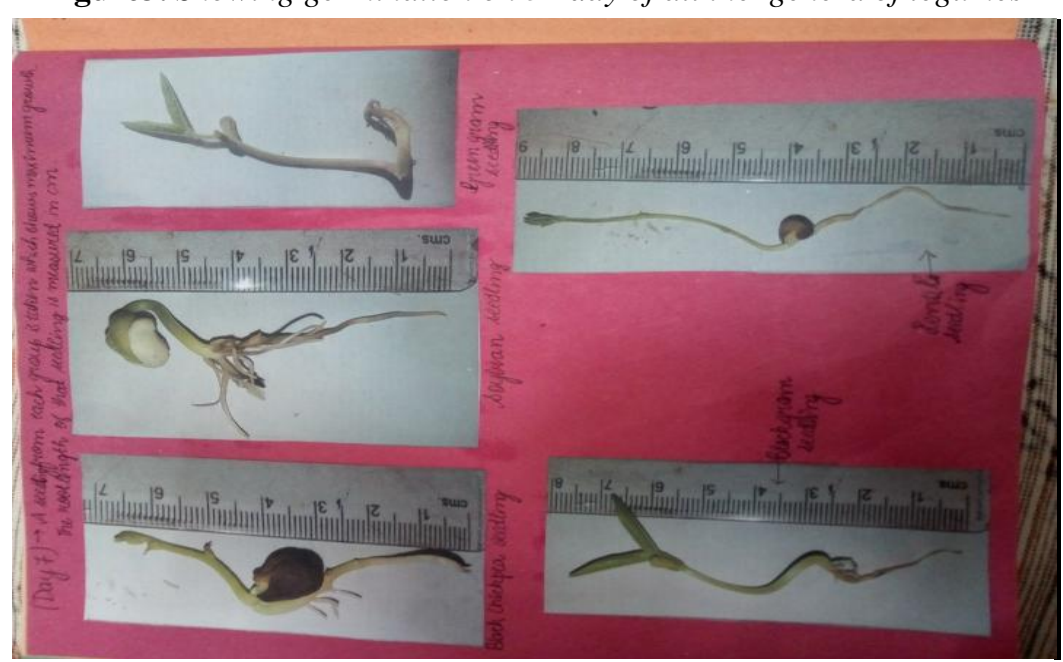

Figure4. Showing germination with maximum growth on $7^{\text {th }}$ day

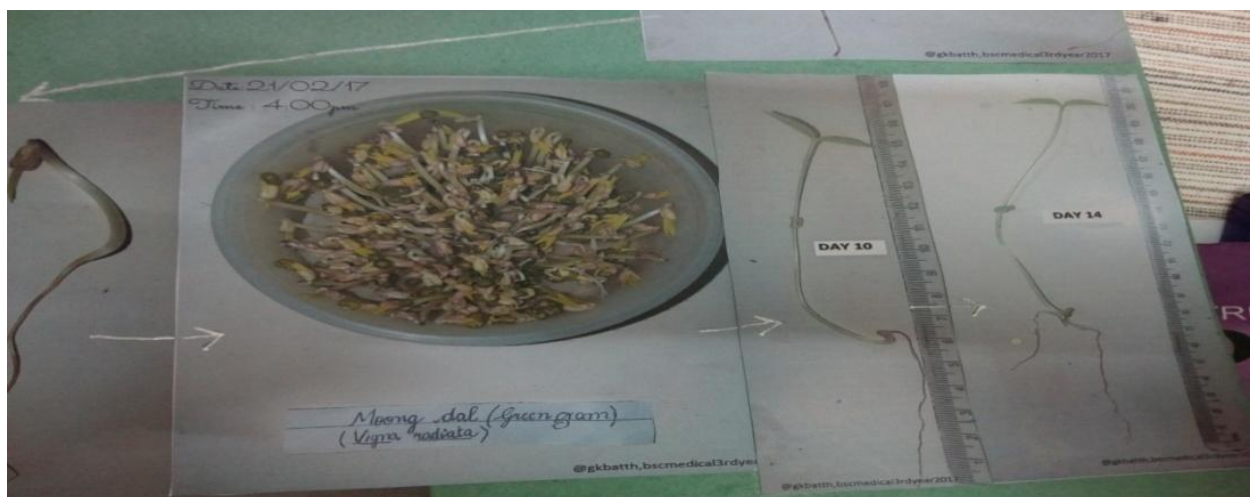

Figure5. Showing maximum germination on $10^{\text {th }}$ and $14^{\text {th }}$ day in Vigna radiata $($ V.I. $=788.5)$ 


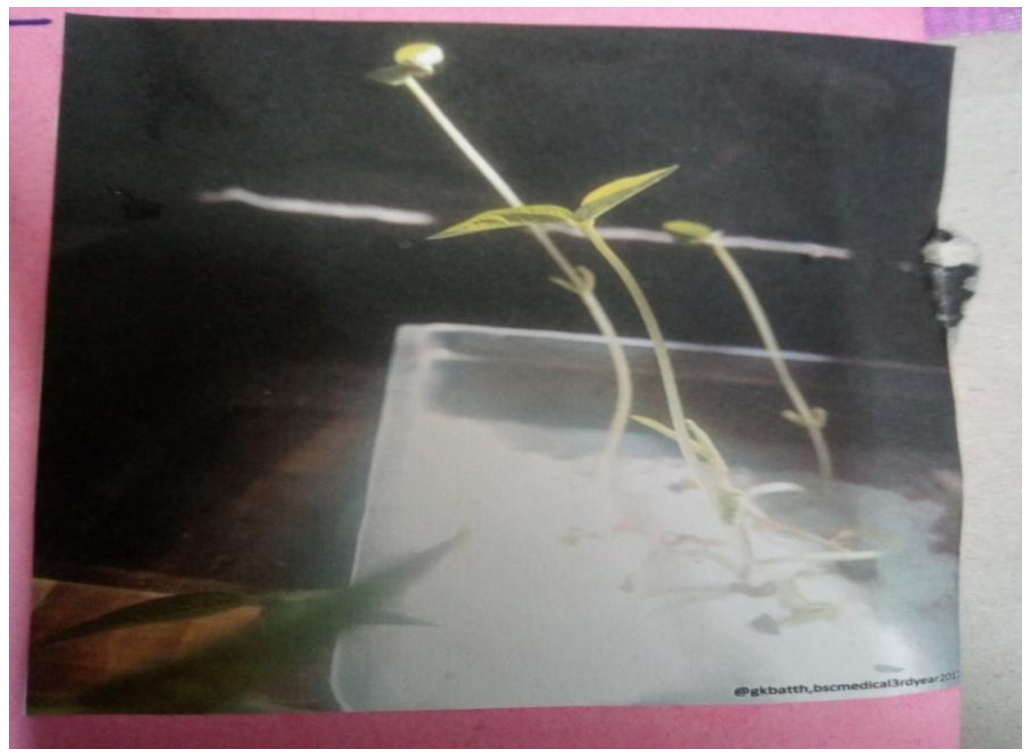

Figure6. Showing best viability of Trigonella after $14^{\text {th }}$ day

The seeds were observed daily and the number of seeds germinated and their respective root length were recorded for 14 days. Emergence of radical was the indicator of seed germination. Seeds were observed each day and it was found that germination percentage was maximum (100\%) in two genera i.e Vigna munga and Lens culinaris but their vigour index was lesser than the seeds which showed 88\% Germination i.e Trigonella as shown in figure 1 and Table 1 showing the respective root length in all the genera. It was found that when Cicer arientum was placed near the seeds, germination stopped. But when later seeds of Cicer arientum was replaced by Vigna radiate, germination resumed and showed growth suggesting the presence of inhibitor in Cicer arientum. Many orthodox seeds can be stored for 50-100 years, under conditions of low temperature and low water content ${ }^{5}$.Similar results were found in bamboo seeds where Germination studies and Vigour index studies were done in three species ${ }^{6}$. Similar result were obtained in seeds of soybean ${ }^{7}$ (Glycine max) where a decrease in germination and vigour index occurred with increase in storage period. It showed that safflower (Carthamustinctorious) seeds when stored in cloth bags under ambient conditions, showed a decline in germinability by $12.57-17.28 \%$ after 28 months and $35.17 \%$ after 20 months ${ }^{8}$.Seed moisture content significantly influenced the germination percentage of the seeds and the seed viability loss was increased with increasing moisture content ${ }^{9}$.

\section{Conclusion}

Out of all the six genera of legumes, Trigonella foenum-graecum has the highest vigour index (1192) and Glycine max has the lowest vigour index (376). Though Lens culinaris and Vigna radiata showed maximum germination percentage of $100 \%$ but vigour index of both were 400 and 788.5 which was lesser than the Cicer arientum whose G\% is $95 \%$.Vigour Index shows the better viability as compared to Germination percentage.

\section{ACKNOWLEDGEMENT}

The senior author is thankful to DBT for providing the necessary facilities for carrying out the research

\section{REFERENCES}

[1] Tilebeni G H and Golpayegani A. (2011). "Effect ofseed ageing on physiological and biochemical changesin rice seed (Oryza sativa L.)", International Journal of AgriScience, Vol. 1, No. 3, pp. 138-143.

[2] MosaviNik S M, Gholamitilebeni H, Kordfirouzjae GH, Sadeghi M and Sedighi E. (2011). "Free fatty acid and electrical conductivity changes in cotton seed (Gossypiumhirsutum) under seed deteriorating conditions", International Journal of Agri Science, Vol.1, No. 2, pp. 62-66.

[3] Richa, M.L. Sharma, and Neeru Bala. (2006). Studies on endogenous levels of plant growth hormones in relation to seed viability in some bamboo seeds. Indian J. Pl. Physiol., 11(4):358363. 
[4] Roberts, E.H. 1972. Loss of viability and crop yields. In: Viability of seeds (ed.) E.H. Roberts, Chapman and Hall Ltd., London, P. 313.

[5] Roos, E.E. and D.A. Davidson. (1992). Record longevity of vegetable seeds in storage. Hortscience, 27:393-396.

[6] Geetika, Richa and M.L Sharma (2016).Effect of Prolonged Storage on the Biochemical Constituents of Primary Metabolites in Three Species of Bamboo Seeds. 39(1): 248-250

[7] Narayanaswamy, S., M. Ravikumar and R. Sreerama (2000). Storability of soybean (Glycine $\max (\mathrm{L}$.$) Merill) seed as influenced by packaging. Mysore J. Agric. Sci.,34: 227-232.$

[8] Shekhargouda, M., G.N. Kulkarni and V.C. Patil.(1997). Seed invigouration in safflower (Carthamus tinctorius L.) Mysore J. Agric. Sci.31:205-208.

[9] Lakshmi C J., Seethalakshmi K K., Chandrasekhara pillai P K and Raveendran V P. (2014).Seed attributes and storage behaviour of the edible bamboo Dendrocalamus brandisii (Munro) Kurz. Proceedings of the 26th Kerala Science congress, 28-31 January 2014,KVASU, Wayanad. 206207.

\section{AUTHOR'S BIOGRAPHY}

Dr Geetika singh, working as Assistant professor in MCM DAV College, Chandigarh. She has qualified CSIR NET, ICMR JRF and GATE. She has more than 12 publications so far. 